\title{
On-Demand Satellite Payload Execution Strategy for Natural Disasters Monitoring Using LoRa: Observation Requirements and Optimum Medium Access Layer Mechanisms
}

\author{
Lara Fernandez ${ }^{1,2,3, *}$, Joan Adria Ruiz-de-Azua ${ }^{4}$, Anna Calveras ${ }^{2}$ and Adriano Camps ${ }^{1,3}$ \\ 1 CommSensLab-UPC, Department of Signal Theory and Communications, UPC BarcelonaTech, \\ 08034 Barcelona, Spain; adriano.jose.camps@upc.edu \\ 2 Department of Network Engineering, UPC BarcelonaTech, 08034 Barcelona, Spain; anna.calveras@upc.edu \\ 3 Institut d'Estudis Espacials de Catalunya (IEEC)-CTE-UPC, 08034 Barcelona, Spain \\ 4 i2Cat Foundation-Space Communications Research Group, 08034 Barcelona, Spain; joan.ruizdeazua@i2cat.net \\ * Correspondence: lara.fernandez.c@upc.edu
}

\section{check for}

updates

Citation: Fernandez, L.;

Ruiz-de-Azua, J.A.; Calveras, A.;

Camps, A. On-Demand Satellite

Payload Execution Strategy for

Natural Disasters Monitoring Using

LoRa: Observation Requirements and

Optimum Medium Access Layer

Mechanisms. Remote Sens. 2021, 13,

4014. https://doi.org/10.3390/rs

13194014

Academic Editor: Nikos Koutsias

Received: 10 August 2021

Accepted: 27 September 2021

Published: 7 October 2021

Publisher's Note: MDPI stays neutral with regard to jurisdictional claims in published maps and institutional affiliations.

Copyright: (C) 2021 by the authors Licensee MDPI, Basel, Switzerland. This article is an open access article distributed under the terms and conditions of the Creative Commons Attribution (CC BY) license (https:/ / creativecommons.org/licenses/by/ $4.0 /)$.

\begin{abstract}
Natural disasters and catastrophes are responsible for numerous casualties and important economic losses. They can be monitored either with in-situ or spaceborne instruments. However, these monitoring systems are not optimal for an early detection and constant monitoring. An optimisation of these systems could benefit from networks of Internet of Things (IoT) sensors on the Earth's surface, capable of automatically triggering on-demand executions of the spaceborne instruments. However, having a vast amount of sensors communicating at once with one satellite in view also poses a challenge in terms of the medium access layer (MAC), since, due to packet collisions, packet losses can occur. As part of this study, the monitoring requirements for an ideal spatial nodes density and measurement update frequencies of those sensors are provided. In addition, a study is performed to compare different MAC protocols, and to assess the sensors density that can be achieved with each of these protocols, using the LoRa technology, and concluding the feasibility of the monitoring requirements identified.
\end{abstract}

Keywords: natural disasters; sensors; satellite communications; constellations; CubeSats; IoT; LoRa; MAC protocols

\section{Introduction}

Natural disasters cause the loss of lives and assets, leaving a dent in the society, and the economy of the affected regions. These losses can be minimised by monitoring systems that may provide continuous information and early warnings in the areas at risk. However, for these monitoring systems to be performant, it is necessary to have dense coverage, and near real-time data, to be able to react to a potential natural disaster occurring.

One of the current monitoring and early warning systems for natural disasters are the networks of in-situ instruments, placed on the Earth's surface. Often, instruments such as buoys or profiling floats are placed in remote areas and need satellite communications to retrieve the data. Some use geostationary orbit (GEO) satellites, such as INMARSAT or the global telecommunication system (GTS) [1], since permanent coverage of the areas, except the poles, is ensured. Others use polar low earth orbit (LEO) satellite constellations, which provide global coverage, and the transmitted power is significantly lower. Either of these solutions often requires the in-situ instruments to have custom ad-hoc proprietary hardware, that is not modular. Moreover, once the satellite has retrieved the data, they have to be downloaded to the ground, which introduces a non-negligible latency. An example is the National Oceanic and Atmospheric Administration (NOAA) [2] tsunami detection and monitoring buoys that have a latency of between 25 and $60 \mathrm{~min}$ [3].

Another type of in-situ instruments are arrays of sensors located along the coastlines and on the land. Usually, they use a base station to retrieve the data, following a star-shaped 
topology, i.e., all instruments communicate independently with the nearest base station. Contrarily to the buoys example, the data of these sensors have a small latency, since these base stations have direct access to the monitoring and surveillance network. However, given the location of these sensors, the alert is given when the natural disaster has already reached populated areas. An example of such a system is the one deployed by NOAA along the United States and Canada coastlines [4], to monitor ocean currents, wind, water levels, etc., and also detect tsunamis. Additionally, in California, the ShakeAlert [5] system has been deployed. It consists of a series of seismic sensors placed in strategic areas that alert users whenever there is a potential risk of an earthquake.

Aside from in-situ instruments, satellites are also used for natural disaster monitoring. Earth observation (EO) satellites can carry payloads, such as synthetic aperture radars (SAR), radiometers, or optical imager spectrometers, among others [6], that have been proven to be useful in natural disaster monitoring and early warning systems. For instance, the data from the moderate resolution imaging spectroradiometer (MODIS) [7] sensors are used to create fire detection maps [8]. Additionally, an algorithm has been developed to identify areas that will be affected by drought [9]. However, to have a high percentage of the Earth's surface covered, satellite payloads should be executed constantly and possibly many sensors on-board many spacecraft are needed. Often, satellite platforms have limited resources, particularly in terms of power and data, which conditions the duty cycle of the payloads to be executed to a limited extent each orbit. This implies that some payloads may not be able to execute during the whole orbit, because there is not enough power, or even if they do, it might not be feasible to download the data generated during the contacts with the ground station. For instance, Sentinel-1 [10] carries a C-Band SAR instrument that can only be executed during $30 \%$ of the orbit [11], or the coastal zone colour scanner (CZCS) that flew on-board the Nimbus 7 satellite with a duty cycle of $10 \%$.

Overall, both in-situ instruments and EO payloads contribute to detect and monitor natural disasters. However, comparing the requirements identified in 2013 by the United Nations (UN) as part of the "Value of Geoinformation and Risk Management: benefits analysis and stakeholder assessment (VALID)" [12] study, with the in-situ instruments, the density of sensors and the latency at which the information is available is insufficient. Additionally, a similar issue happens with EO satellite payloads, due to the duty cycle limitation. As part of the study presented in our paper, a new paradigm for natural disaster monitoring called on-demand satellite payload execution is presented. This paradigm combines a network of sensors deployed on the surface of the Earth with satellite EO payloads. It offers an optimisation to current monitoring systems, by having the density of sensors required for monitoring, and the flexibility to have different types of sensors for each of the natural disasters. Thus, when a sensor (or sensors) detects an event, they will send the data to a satellite and will wake up the satellite payload on-demand. This way, satellite payloads are executed specifically over areas where it is really necessary, although it was not originally foreseen, saving resources. Moreover, with this early notification, natural disasters can be detected prematurely, leaving time to react and reduce the overall number of casualties.

In this article, as a contribution to the on-demand execution paradigm, an architecture for the paradigm is proposed. Additionally, the monitoring requirements of the different natural disasters are identified. Being the crucial requirements: the spatial density of nodes, the update frequency of the measurements, and the update frequency when a critical event occurs. Given that, having a certain density of nodes transmitting simultaneously can be challenging in terms of MAC protocol. Then, for this particular case, a survey of different MAC layer mechanisms used for IoT communications with satellites [13] is conducted, and the maximum density of nodes that can be deployed with each of the protocols is computed and compared to the monitoring requirements.

This study is organised as follows: Section 2 contains the proposed architecture for the on-demand paradigm. Section 3 presents the requirements for each of the disaster monitoring use cases, identifying the types of sensors that can be used for each case. 
Section 4 presents the different MAC layer mechanisms and defines the packets' size. Section 5 presents the results on the maximum number of nodes that the network can handle for each of the MAC layer mechanisms. Section 6 contains a discussion of the results obtained. Finally, Section 7 presents the conclusions.

\section{On-Demand Satellite Payload Execution Strategy Architecture}

The architecture proposed in this article for the on-demand satellite payload execution strategy has to offer global coverage and be modular. However, additionally, the costs for deploying the constellation and network of sensors have to be kept low. A visual representation of the scenario is shown in Figure 1. In the scenario, there are the Earthbased sensors located on the Earth surface and also there are the satellite or satellites. It can be seen that when one or multiple Earth-based sensors detect a warning, this is forwarded to the satellite, and the satellite can then execute an EO payload if necessary.

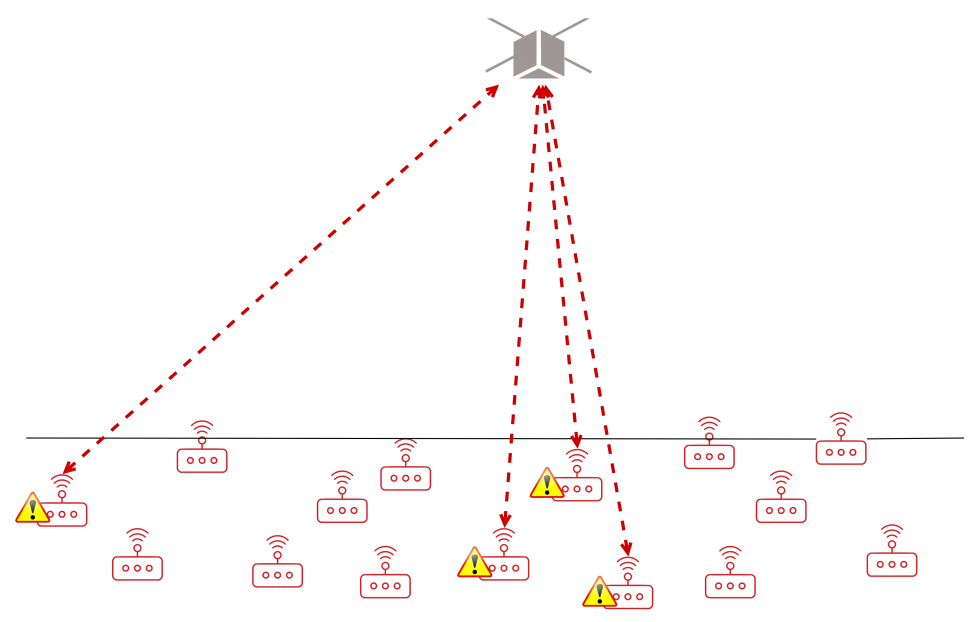

Figure 1. Visual representation of the on-demand satellite payload execution scenario.

For the space segment, a constellation of LEO satellites may be a suitable solution [14]. As compared to GEO satellite constellations, this constellation can provide global coverage, low latency, and low communication losses. Moreover, since the emergence of the CubeSat standard [15], massive production of the satellite avionics has boosted, and launch costs slightly reduced. Additionally, some EO payloads that were considered either problematic or not feasible for CubeSats in 2012 [16], they are now flying in various CubeSat-based missions [17].

Additionally, concerning the Earth-based sensors, the emergence of the Internet of Things (IoT) paradigm can be a solution to these flexible sensor networks. IoT are devices (or "things") that can sense, transmit and receive information, and can connect to a network, such as the Internet, or other private networks. In recent years, IoT technologies classified as a low power wide area network (LPWAN) [18] have emerged, having longer communication ranges, while still having a low power consumption. This enables the deployment of IoT devices in rural areas. Each of these devices communicates independently with a gateway or base station, which is then connected to the network, for the data to be available. However, in remote areas, where placing gateways requires the deployment of a considerable infrastructure, satellites are used to communicate with the devices [19].

The main LPWAN technologies are: Sigfox [20], NB-IoT [21], and LoRa [22]. Out of these, for various different reasons, LoRa seems to be the most promising one for satellite communications. First of all, LoRa devices transmit in the ISM bands, making unnecessary any type of licensing or contracting services from private companies. Additionally, although the MAC mechanism is by default LoRaWAN [23,24], it can be customised, and whichever protocol the user requires can be implemented. Additionally, the architecture is modular, so the devices can either communicate to a gateway using LoRaWAN, or to other devices or gateways, with other protocols. Moreover, since the modulation can 
compensate the Doppler effect experienced from a LEO [25], it is capable to communicate ground devices and satellites, just adding some complexity to the satellite transceiver [26]. Finally, LoRa devices can include multiple sensors that measure different parameters. This ensemble of device and sensor is referred to as a node.

\section{Ground Nodes Requirements Identification}

This section presents the requirements identified for each of the natural disasters, in terms of spatial node density, update frequency, and critical update frequency of the readings. This spatial node density determines how close or apart the nodes are located on the Earth's surface. The update frequency determines how often nodes have to retrieve measures if no risk of natural disaster is detected. However, if a risk is detected, the nodes may take measurements more frequently, and this is identified in our study as the critical update frequency. The reference study to identify these requirements is VALID [12]. However, this study was done assuming that the observations were done from satellite EO payloads. Thus, it identifies resolution requirements for the payloads, which are assumed to be the radius that the nodes cover in our study.

Aside from the requirements, the necessary sensors that each node shall include are also identified. To select these sensors, first, the state of the art of natural disaster monitoring using IoT is surveyed. Then, out of the sensors identified in these studies, the ones with available commercial solutions are considered in our study.

The natural disasters identified [12] are floods, landslides, forest fires, sea ice, earthquakes, droughts, and tsunamis. The particular study for each of the cases can be found in the subsections below. Table 1 summarises the requirements, and necessary measurements for each disaster.

\subsection{Floods}

To monitor flooding events using IoT technologies, several sensors can be used. In [27] a flooding monitoring system using IoT ultrasonic sensors is proposed. Additionally, Nevon Projects [28] provide an IoT kit for flooding monitoring, including rain and water sensors. Finally, Envira IoT [29] has a real-time warning system that uses IoT technologies with sensors, although the particular types of sensors are not specified. Among the solutions available, the ultrasonic, rain, and water sensors are considered in our study.

To determine the spatial node density of nodes and the update frequency, the VALID study [12] identifies the specific requirements for flood risk mapping and flooded areas. In the case of flood risk mapping it is identified that one node should be placed every $1 \mathrm{~km}$ and for flood risk mapping every $0.25 \mathrm{~km}$. For our study a midpoint between the two requirements is chosen, having one node cover $0.5 \mathrm{~km}$ in radius. Overall, it leads to a spatial node density of 1273 nodes $/ 1000 \mathrm{~km}^{2}$. The update frequency in the VALID study [12] is stated to be less than one week, for flood risk mapping, and from hours of up to 1 day, for flooded areas. In our study, these two requirements will be considered for the update frequency, and the critical update frequency, respectively.

\subsection{Landslides}

In [30] an IoT monitoring system using IoT is proposed. As part of that study soil moisture sensors, pressure piezometers, strain gauges, tilt-meters, geophones, rain gauges, and temperature sensors are identified. Having all those sensors would be ideal, however, only soil moisture, rain, and temperature sensors are broadly available. Additionally, in [31] two different modules are used for IoT landslide monitoring. One of these modules is a weather monitoring station, and the other one has to be placed on the ground. The weather monitoring station measures the air temperature, relative humidity, barometric pressure, rainfall, and wind speed, whilst the ground monitoring station contains a gyroscope, a compass, a GPS, an accelerometer, and a soil moisture sensor. Thus, as part of our study accelerometers, soil moisture, rain, temperature sensors, and anemometers are considered. 
Table 1. Summary of required measurements, sensors used, spatial node density, and update frequency for the cases identified.

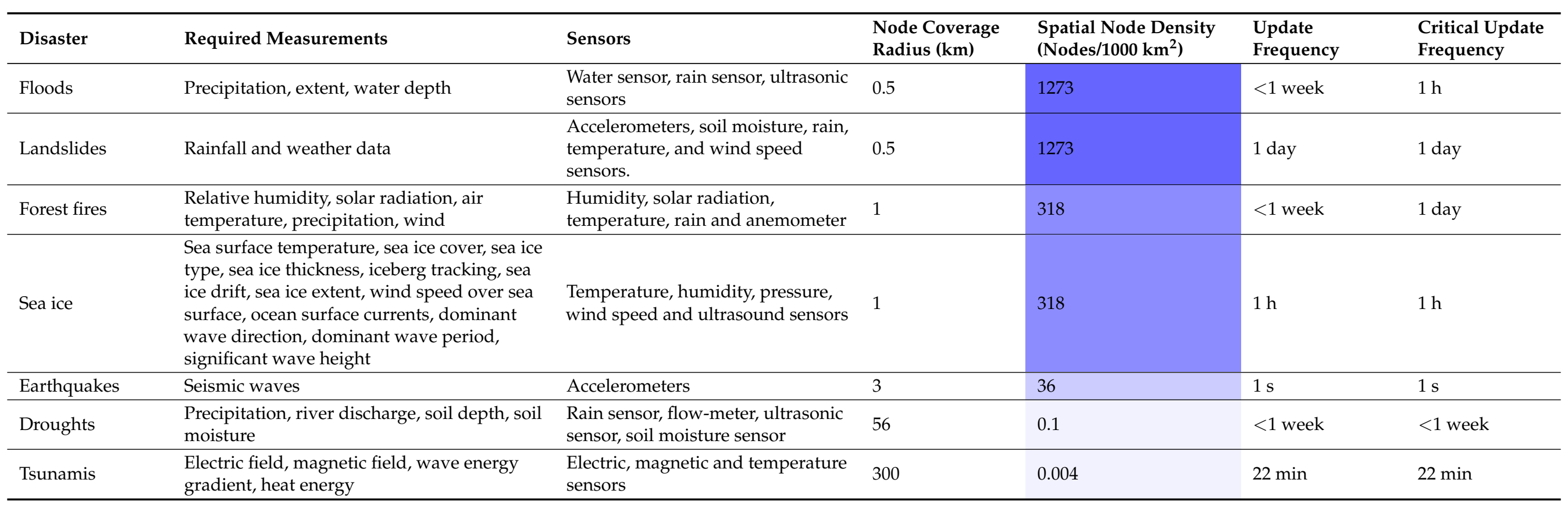


To identify the requirements, the VALID study [12] states that, to study areas prone to landslides, one node should be located every $10 \mathrm{~m}$. However, this is a very restrictive requirement for nodes. To determine an optimum requirement, the mean distance between landslides has been calculated from the landslides database in the U.S. Landslide Inventory [32]. Selecting an area with has high landslide activity, such as the West Coast, it can be seen that these events are generally $5 \mathrm{~km}$ apart, but for this study, a safety margin of 10 is taken. Thus, in our study the most restrictive requirement is that nodes cover $0.5 \mathrm{~km}$ in radius, leading to a spatial node density of 1273 nodes $/ 1000 \mathrm{~km}^{2}$. For the update and critical update frequencies, the value of 1 day, from VALID, is considered in our study.

\subsection{Forest Fires}

In [33], the benefits of using IoT sensors for fire monitoring were identified. For instance, the fire that occurred in the Notre-Dame cathedral in July 2020, could have been detected earlier, preventing damage, if an IoT system had been installed. Additionally, in [34], an architecture for a monitoring solution is proposed, placing sensors both in rural and urban areas, using satellite communications and gateways to connect the sensors. In this study, the sensors identified for fire monitoring are temperature, humidity, solar radiation, and smoke. Thus, the sensors considered in our study are the previous ones and an anemometer, as it could be useful to predict the fire direction of propagation.

Again, the requirements identified are based on the VALID study [12]. In this study, it is stated that the monitoring of areas prone to wildfire risk due to natural or human factors, should have nodes cover between 0.25 to $1 \mathrm{~km}$ in radius. As part of our study, the more relaxed requirement of $1 \mathrm{~km}$ is considered, since having nodes cover a quarter of a $\mathrm{km}$ is restrictive compared to $1 \mathrm{~km}$. This provides a spatial node density of 318 nodes $/ 1000 \mathrm{~km}^{2}$. Regarding the update frequency, the VALID study states that less than one week is enough, and for critical update frequency measures should be taken once a day. These two update frequency requirements are the ones considered in our study.

\subsection{Sea Ice}

Although sea ice cannot be considered a natural disaster, in recent years it has been a hot topic, due to the sea level increase [35], and because of the opening of commercial navigation through the Arctic. Thus, it is also considered as part of our study. To identify the requirements for our study, the cases presented in [36] are considered. This study identifies the different measurements, and resolution requirements required to monitor sea ice.

In [37] different monitoring systems for the oceans were surveyed, identifying sensors to measure the main physical parameters. These are temperature, humidity, pressure, wind speed, and wind direction sensors. Aside from ocean monitoring, also sea ice monitoring is critical, Smartice [38] proposes to monitor sea ice thickness with a snowmobile. Although Smartice does not clarify the types of sensors used for this purpose, some other studies [39] suggest the use of ultrasonic sensors to measure sea ice thickness. Overall, as part of our study, the sensors considered are temperature, humidity, pressure, wind speed, and ultrasonic sensors.

The requirements identified in [36] for the applications that can be covered using IoT nodes have resolution requirements ranging between 1 and $25 \mathrm{~km}$. The most restrictive requirement of having 1 node cover $1 \mathrm{~km}$ in radius, is considered for our study, providing a spatial node density of 318 nodes $/ 1000 \mathrm{~km}^{2}$. The update frequency in the article is set to $1 \mathrm{~h}$, so the same requirement is assumed for our study.

\subsection{Earthquakes}

When monitoring earthquakes it is necessary to detect seismic waves first. These seismic waves can be classified as primary, secondary, and surface waves. To detect these seismic waves in-situ it is necessary to do it with accelerometers, to sense the movement. For instance, in [40] a specific device using an IoT technology is proposed, comparing 
the performance of four different accelerometers. Additionally, in [41] a Zigbee-based monitoring system is proposed. Moreover, there are already some early warning systems deployed, such as ShakeAlert [5], but neither cover the whole globe, nor have the optimum spatial nodes density.

The spatial nodes density is selected based on the dimensions of the epicenter of the earthquake so that the coverage radius of nodes is the same as the earthquake's center. This way, earthquakes will be detected as soon as they start occurring. Looking at the latest earthquakes database from the U.S. Geological Survey [42], it can be seen that the epicenter of most earthquakes has between 3 and $5 \mathrm{~km}$ in radius. Thus, the most restrictive case of having a node cover $3 \mathrm{~km}$ in radius is considered for our study, which gives a spatial node density of 36 nodes $/ 1000 \mathrm{~km}^{2}$.

To determine the update frequency of the nodes it should be noted that the monitoring of earthquakes is extremely time-constrained since seismic waves travel at rapid velocities. For instance, the primary wave travels at a speed of $13 \mathrm{~km} / \mathrm{s}$, whilst the secondary wave varies in speed depending on the medium that it is travelling in, and it can range from 1 to $8 \mathrm{~km} / \mathrm{s}$. These secondary waves are the ones that can be sensed with accelerometers, so the speed of these waves is used to compute the update frequency for the nodes. Considering the coverage radius between the nodes, it would take $0.37 \mathrm{~s}$ in the worse case and $3 \mathrm{~s}$ in the best case for the wave to travel from one node to the next one. Given that $0.37 \mathrm{~s}$ is very restrictive for IoT systems, $1 \mathrm{~s}$ of update frequency is chosen for our study.

\subsection{Droughts}

In [43] a framework to perform drought prediction is proposed, identifying the sensors that can contribute to drought prediction. These are piezometers, groundwater level, water flow, soil moisture, and tensiometer sensors. However, comparing the sensors mentioned with current IoT solutions only water flow and soil moisture sensors were found. Moreover, groundwater level sensors were not specifically found, ultrasonic sensors can also detect water contents, and also rain sensors can contribute to the monitoring and identification of the water contents. Overall, the sensors considered as part of our study are water flow, soil moisture, ultrasonic, and rain sensors.

The definition of the requirements is based on the U.S. drought monitoring system [44], which provides regular maps of risk areas. Overall, a spatial node density of 0.1 nodes $/ 1000 \mathrm{~km}^{2}$ with an update frequency of less than one week is considered in our case.

\subsection{Tsunamis}

There are already some proposals using IoT sensors to monitor tsunamis. For instance, in [45], an architecture consisting of an underwater WSN is presented, with relay nodes connected to a cloud. Additionally, in [46] it is proposed to use the induced electric, and magnetic fields, the wave energy gradient, and heat/chemical energy sensors. For our study, these same four sensors will be considered.

To determine the spatial nodes density, current monitoring systems are surveyed, one of them is the NOAA system [47]. These buoys are placed approximately $300 \mathrm{~km}$ apart and distributed along the coastlines, with a total of 389 meteorological stations deployed in the U.S. Additionally, the Argo profiling floats [48] is another system that monitors the oceans and implements a tsunami warning system. There are a total of 4600 floats distributed along the oceans, most of them along the Pacific and Atlantic oceans. To assess if the density of these current monitoring systems is enough, it is necessary to see the speed at which tsunamis propagate. This velocity depends on the depth of the ocean, so it can range from $800 \mathrm{~km} / \mathrm{h}$ down to $30 \mathrm{~km} / \mathrm{h}$ [49]. Since the maximum speed is $800 \mathrm{~km} / \mathrm{h}$, having buoys $300 \mathrm{~km}$ cover is a good requirement, which provides a spatial node density of 0.004 nodes $/ 1000 \mathrm{~km}^{2}$. In terms of the update frequency, the minimum travel time from one node to the other is $22 \mathrm{~min}$, so these requirements are the ones considered for our study. 


\section{Medium Access Layer Mechanisms Survey}

In this section, the best suited protocols for IoT satellite communications are presented for our case study. These are evaluated for the LoRa modulation, to determine the density of nodes that can communicate with a satellite at a given time. To obtain this density, the packets exchanged in the network, their fields, and sizes have been identified. Moreover, the assumptions considered for each of the protocols are also stated.

MAC protocols have been extensively studied for the LoRa modulation. The most frequently used one is LoRaWAN [23,24], proposed by the LoRa Alliance, and it uses an extensive network of gateways denominated the Things Network. However, it has been demonstrated that this MAC protocol has certain capacity limitations [50-52]. Aside from LoRaWAN, other protocols have been studied to enhance the capacity and the range of LoRa networks. Some studies propose to use different spreading factors or scheduling to benefit from the co-channel rejection $[53,54]$. Other studies propose using time division multiple access-based protocols [55,56]. Additionally, some propose protocols that sense the medium, such as CSMA/CA [57]. However, all these studies consider an architecture where the nodes are always in range of its gateway. In the particular scenario considered as part of our study, the satellite is the gateway, which is orbiting in LEO and is not always available for the nodes. Additionally, if instead of one satellite there is a constellation, the nodes would not always be communicating with the same satellite.

Apart from the protocols studied specifically for LoRa, protocols used for regular satellite communications have been considered [58] for our study. However, most of these protocols are not well suited for IoT satellite communications, since the link considered is from one satellite to one ground station, but not for high density scenarios where there is more than one node accessing the medium.

Overall, the best suited protocols for IoT satellite communications scenario were identified in [13], where a survey of state of the art proposed protocols is presented providing metrics of maximum normalised throughput and a trade-off between complexity, energy efficiency, and scalability. These are the ones that have been considered in our study. It should be noted that all protocols are compliant with the $1 \%$ duty cycle restriction stipulated by the International Telecommunication Union (ITU) [59].

In this section, first, the scenario considered for the different packets exchanged is presented. Then, the different protocols are explained. These protocols are classified depending on the medium usage, being the classifications random access asynchronised protocols, random access synchronised protocols, medium sensing protocols, reservation protocols, and hybrid protocols. For each of them, the sequence diagram is presented, showing the handling of the medium and the packets that are going to be exchanged in the network, as well as its fields.

\subsection{Scenario}

Our particular case study considers a scenario where satellites receive the messages sent by the nodes. These satellites are in polar LEO orbits, and the nodes are located on the Earth's surface. Given the low altitude of the satellites, these are not seen as static from Earth. In fact, from a fixed point on Earth, a satellite in LEO is only seen between 8 and 10 min depending on the latitude and longitude, where the node is located. This creates a disruption from the nodes' point of view since they might not know when a satellite is available to transmit an alert. For that reason, the satellite transmits a periodic beacon (every $8 \mathrm{~min}$ in our study), ensuring that all nodes receive a beacon and are aware that a satellite is ready to transmit data or execute the satellite's payload on-demand.

Aside from the beacon, also data packets, acknowledgement (ACK) packets, and control packets are sent. These packets contain different fields and as a consequence have different lengths, depending on the MAC protocol used. These different fields are explained below: 
- Timestamp: the timestamp provides the actual time when sending the Beacon, in Unix timestamp format. This field occupies 64 bits, and it is used to time tag the packets. Both the satellite and the nodes obtain the time from a GPS module;

- $\quad$ Satellite ID: this field provides an identification of the particular satellite sending/receiving the beacon. This is necessary in case a constellation of satellites is launched but can be omitted otherwise. It has a length of 16 bits, and this would allow up to 65,536 satellites to be launched in the same constellation;

- $\quad$ Sync slots: this field is used in slotted MAC protocols to synchronise the slots amongst the satellite and nodes, and also to provide the length, in milliseconds, of the slots. The field has a length of 16 bits which allows enough values to contain the synchronisation and the length of the slots;

- $\quad \mathrm{N}$ slots (number of slots): this field is used in protocols that not only divide the medium into slots but group a number of these slots into a frame. It provides the number of slots within each of the frames. To do that, 16 bits are allocated, to have up to 65,536 different slots per frame;

- Free slots: this field is also used in protocols that not only divide the medium into slots, but group a number of these slots into a frame, and reserve slots within each frame to particular nodes. In this field, 16 bits are allocated, to have up to 65,536 different slots;

- Time window: this field, in $\mathrm{ms}$, is used in protocols that define a time window in which the data packet has to be sent. The field has 16 bits, as these time windows are not larger than 65,536 ms;

- Packet size: this field is used in protocols that limit the maximum packet size sent over the medium. The field has 8 bits reserved, for packets with up to 255 bits of payload data;

- Node ID: this field identifies the node, in particular, that is sending or receiving the packet. This field has 32 bits, to place a maximum of $2^{(32)} \simeq 4.3$ billion nodes on the surface of the Earth, which even for the worse density is enough to offer complete coverage;

- Packet ID: this field identifies the packet that a given node is sending or has sent. The field is reset to 0 after $10 \mathrm{~min}$, so each time the satellite receives a Beacon the packet ID is 0 and it increases as retransmissions occur. This way, this parameter has 8 bits of length, which means that one packet can be retransmitted up to 255 times;

- Position: the nodes also include their position on the Earth, so the satellite knows where to execute the payload. This position is obtained from the GPS module the nodes include. The field has a length of 80 bits;

- Sensors data: this field is variable depending on the natural disaster monitored. As identified in the requirements (Section 3), the number of sensors per node can range between 3 or 5 . For each of the sensors, 16 bits of length, to include the type of sensor, and the data;

- Duration: this field informs on the time that should be reserved or has been reserved to a given node to transmit their data packet. The field has been set to $16 \mathrm{bits}$, so a maximum of $65,536 \mathrm{~ms}$ can be reserved.

\section{Beacon}

The beacon format can be seen in Figure 2a. There are two common fields that all beacons contain, highlighted in blue, and the others may be included or not depending on the protocol used. It should be noted that independently from the protocol used the beacon can be considered collision free since the nodes are in receiving mode until they receive this packet.

\section{Data packets}

The data packets, which are presented in Figure $2 b$, are the packets that the nodes send to the satellite, asking for a specific execution. These packets include the sensors' data, and based on these data the satellite decides which payload to execute. 


\section{Acknowledgement packet}

The acknowledgement (ACK) packets can be seen in Figure 2c. This packet is sent by the satellite whenever a data packet is correctly received. It has some common fields, highlighted in blue, which are always sent.

\section{Control packets}

Control packets are used in some particular protocols, that require an orchestration from the satellite to transmit. These packets are the request to send (RTS), and the clear to send (CTS), whose format can be seen in Figures 2d,e.

\begin{tabular}{|l|l|l|l|l|l|l|}
\hline Timestamp (64 bits) & Satelite ID (16 bits) & Sync Slots (16 bits) & N Slots (16 bits) & Free Slots (16 bits) & Time window (16 bits) & Packet size (8 bits) \\
\hline
\end{tabular}

(a) Fields and size of beacon packets

\begin{tabular}{|l|l|l|l|l|l}
\hline Timestamp (64 bits) & Satelite ID (16 bits) & Node ID (32 bits) & Packet ID (8 bits) & Position (80 bits) & Sensors Data (variable) \\
\hline
\end{tabular}

(b) Fields and size of data packets

\begin{tabular}{|l|l|l|l|}
\hline Timestamp (64 bits) & Node ID (32 bits) & Packet ID (8 bits) & Free Slots (16 bits) \\
\hline
\end{tabular}

(c) Fields and size of acknowledgement packets

\begin{tabular}{|l|l|l|l|}
\hline Timestamp (64 bits) & Satelite ID (16 bits) & Node ID (32 bits) & Duration (16 bits) \\
\hline
\end{tabular}

(d) Fields and size of request to send packets

\begin{tabular}{|l|l|l|}
\hline Timestamp (64 bits) & Node ID (32 bits) & Duration (16 bits)
\end{tabular}

(e) Fields and size of clean to send packets

Figure 2. Format of the different packets defined.

\subsection{Random Access Asynchronised Protocols}

Random access asynchronised protocols allow contention-based access to the medium to all devices willing to transmit. The sequence diagram is shown in Figure 3. The packets exchanged are the beacon, which is first sent by the satellite to let the nodes know that they can transmit data, if necessary. After the beacon, the nodes send their data packets. In case of a collision free data packet transmission, the satellite responds with the ACK.

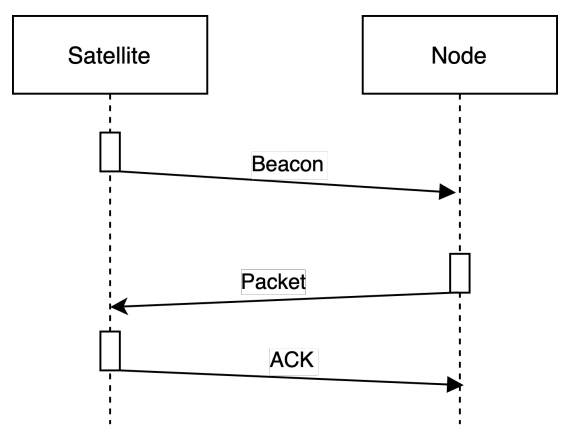

Figure 3. Sequence diagram for random access asyncronised protocols.

These protocols require sending the basic beacon and ACK, with only the common fields. If any other field is necessary, it will be specified in the specific protocol explanation.

\section{Aloha}

The simplest protocol is the Aloha one [60]. The network devices can always send the packets, and it does not have any additional complexity added to it. Thus, once the nodes have received a satellite beacon, they can choose when to transmit in a contention-based manner. If the transmitted data packet has been correctly received, the satellite responds with an ACK. In case the node does not receive any ACK, it re-transmits the packet after a random time-out. 


\section{Enhanced Aloha (E-Aloha)}

The E-Aloha [61] protocol proposes a solution to packets that are transmitted always with the same periodicity, to avoid permanent collisions. The access to the medium is also random, as with traditional Aloha, however, it proposes to fix a time window larger than the transmission time of the packets, so the nodes can select randomly the time at which they transmit within that time window, after receiving the beacon. By having this time window, nodes that have the same periodicity to send packets, vary the instant at which they transmit.

This protocol has the same sequence as the classical Aloha protocol. However, the beacon packet contains also the time window field. Additionally, if the node does not receive any ACK after sending a data packet, it would re-transmit it after a random time-out.

\section{Spread Spectrum Aloha (SS-Aloha)}

The SS-Aloha protocol [62] uses spread-spectrum techniques to separate the channels in which each of the packets are sent. By using a spread-spectrum technique, each of the samples received contains more than one bit [63]. In our particular case study, the sequence diagram is the same as with Aloha.

\section{Enhanced Spread Spectrum Aloha (E-SSA)}

This protocol [? ] combines the same spread-spectrum Aloha technique, as with SSAloha, with a recursive successive interference cancellation (R-SIC) algorithm. This R-SIC algorithm works at packet level and exploits a sliding window on the receiver side, which captures all received packets and discriminates between them based on the spreading sequence, the time offset, and the carrier frequency.

For our case study, the R-SIC algorithm is only implemented in the satellite's receiver, since it is the worse case in terms of density, i.e., all nodes may be trying to transmit their data packets to the satellite. Additionally, thanks to the R-SIC algorithm, nodes do not require to receive an ACK from the satellite. Thus, once the nodes have received the satellite beacon, they transmit the data packet once.

\subsection{Random Access Synchronised Protocols}

Random access synchronised protocols divide the channel into slots, so the nodes in the network can access the medium, starting their transmission at the begging of one of these time slots. These slots have the duration of the transmission time of the packets and have to be synchronised amongst all nodes in the network, so a precise time synchronisation is crucial. The sequence diagram for these types of protocols is shown in Figure 4. As with the asynchronised protocols presented in the previous section, the satellite first sends the beacon (A), so that nodes are aware that they can send their data packets to it. Then, in most cases, a given node transmits the data packet (D), and the satellite responds with an ACK (E) if it has been received correctly. However, some slotted protocols instead of using ACKs, send the same packet multiple times $(\mathrm{F}, \mathrm{G}, \mathrm{H})$.

All random access synchronised protocols send the beacon with the common fields, and the sync slots. The ACK contains solely the common fields.

\section{Slotted Aloha (S-Aloha)}

S-Aloha [65] is similar to Aloha, with the difference that the medium is slotted, and the devices that want to transmit have to wait until one slot begins to transmit the packet. As Aloha, in S-Aloha nodes expect to receive ACKs from the data packets sent. Thus, if no ACK is received, the node retransmits the packet after a random time-out.

\section{Contention Resolution Diversity Slotted Aloha (CRDSA)}

The CRDSA protocol [66], aside from having the medium slotted, implements a successive interference cancellation (SIC) mechanism in the receiver, so it can cancel interferences cancellation with the packets. Additionally, the data packets are sent three times, and no ACK is expected. 
For our case study, the SIC algorithm is only implemented on the satellite receivers side, since it is the critical medium access scenario when all the nodes are trying to send packets to a single satellite.

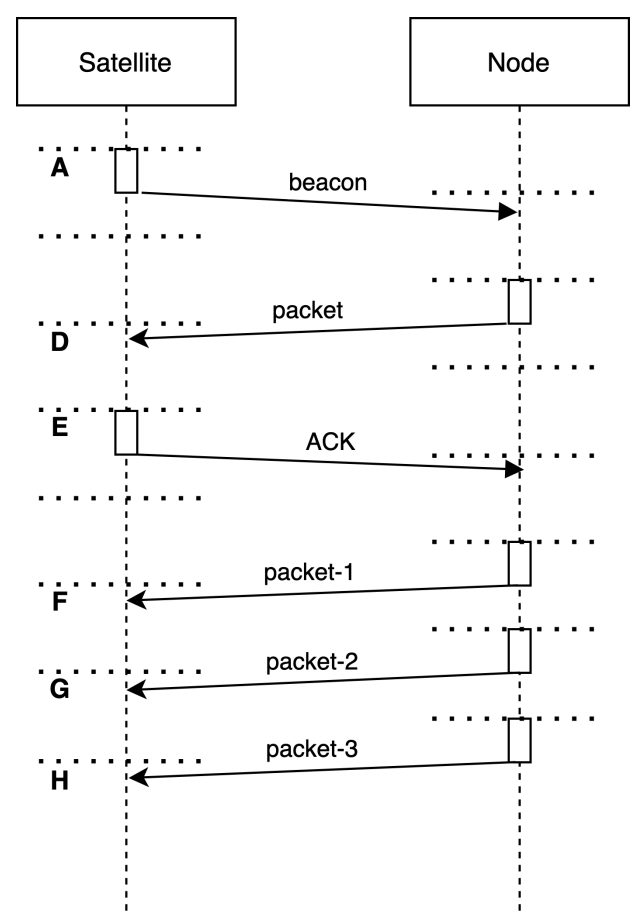

Figure 4. Sequence diagram for random access synchronised protocols.

\section{Irregular Repetition Slotted Aloha (IRSA)}

This protocol [67] is similar to CRDSA, where the nodes also send multiple times the same packet, randomly choosing the slots in which these packets are sent, but the number of copies sent is chosen in an optimised manner.

For our particular case, since the scope of this article is not to optimise the number of redundant packets sent by each node, the same assumption of three packets as in CRDSA is made.

\section{Coded Slotted Aloha (CSA)}

In this protocol, [68] the node divides the packets into different sub-packets of the same length. These packets include error correction codes, and the receiver applies a maximuma-posteriori (MAP) decoder, to be able to recover subpackets that are lost. Additionally, the receiver also implements an interference cancellation scheme to receive from multiple senders. Since it has error correction codes data packets do not require an ACK from the satellite.

In our study, we assume the beacon includes the packet size field, aside from the common ones. Additionally, the division of the packets is done in 112 bits, since it is the size of the beacon, and it would not be practical to divide this packet. This means that any packets that have a payload larger than 112 bits will be divided into subpackets. Finally, regarding the error correction code, according to [68], a forward error correction (FEC) code at physical level is implemented. However, since no details are provided on the code redundancy, the code that adds more redundancy in the LoRa modulation is used. More details on the implementation are provided in Section 5.

\section{Multi-Slots Coded Aloha (MuSCA)}

The MuSCA protocol [69] implements an error correction code for a SNIR, so it can decode packets when there are collisions in a slot. As with CSA protocol, no ACKs are sent when a packet is received. 
The error correction code is a $1 / 4$ Turbo code [69]. The LoRa modulation does not have a $1 / 4$ error correction code, and the code with the largest redundancy is a $4 / 8$. Given this limitation of the LoRa modulation, this case of a redundancy of $4 / 8$ is considered for this study.

\subsection{Medium Sensing Protocols}

Medium sensing protocols function by "listening" to the channel before transmitting. If it is busy the node performs a random back-off, and senses the medium again, until it is free to transmit.

\section{Carries Sense Multiple Access/Collision Avoidance with RTS/CTS (CSMA/CA)}

In CSMA/CA with RTS/CTS [70] once the node has sensed that the medium is free, it transmits the request to send (RTS) packet, and if it is received and the medium is free, the receiver responds with a clear to send (CTS), reserving the channel to that particular node. Once the node receives the CTS, it sends the data packet, which has to be acknowledged. The sequence diagram for CSMA/CA can be seen in Figure 5. As it can be seen in the diagram, only the data packets require the RTS/CTS, since no collisions can be assumed for the beacon.

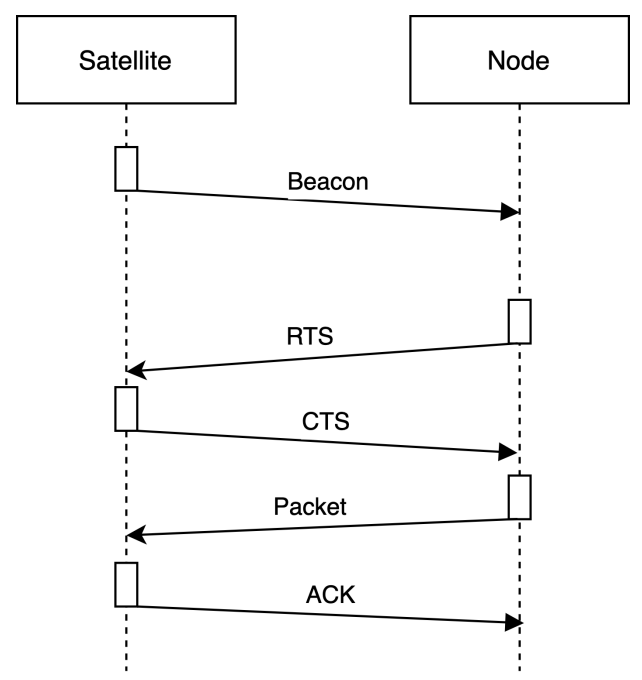

Figure 5. Sequence diagram for CSMA/CA with RTS/CTS medium sensing protocol.

Regarding the format of the packets this protocol sends the regular beacon, data packet, and ACK with the common fields, and also the RTS and CTS control packets.

\subsection{Reservation Protocols}

Reservation protocols divide the medium into different slots and reserve certain slots of the medium to certain nodes. In these protocols, nodes have to be aware of which slots are reserved, and which ones are free. Given that this protocol has also a division of the medium, it also requires precise time synchronisation as the random access synchronised protocols do.

\section{R-Aloha}

R-Aloha [71,72] defines frames, which are further divided into several slots. Nodes can transmit randomly in any of these slots within a frame, and if the communication has been successful (i.e., an ACK is received) that slot is reserved for that node. Contrarily, if no ACK is received the node tries another slot in the following frame. The frames and the collision of messages in a slot and reservation for this protocol are shown in Figure 6. In the Figure, the packets Node 1 to 4 represent the data packets for each of the Nodes. 


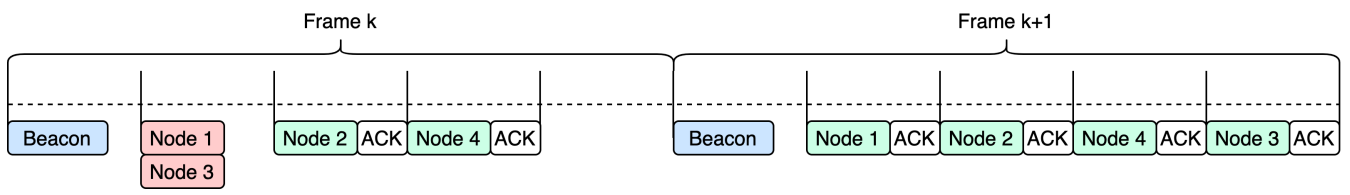

Figure 6. Sequence diagram for R-Aloha reservation protocol.

For this protocol, the beacon includes a sync, number of slots, and free slots fields, aside from the common fields. In the case of the ACK, it also contains the free slots field. Moreover, given that in this protocol the beacon has to be sent at the beginning of each frame, the periodicity of the beacon cannot be considered to be the $8 \mathrm{~min}$ fixed for the rest of the protocols. Thus, for our study it is assumed that the frames have a 1 min length, sending one beacon each minute. This would allow having up to 8 retransmissions for the data packet of each node. It should be noted that this beacon can still be considered collision free since the nodes know when to expect it.

\subsection{Hybrid Protocols}

Hybrid protocols combine different traditional medium access techniques, and cannot be classified in the previously mentioned sections.

\section{Fixed Competitive Time Division Multiple Access (FC-TDMA)}

In this protocol, [73] the channel is divided into frames, and each of these frames contains a configurable number of slots. The nodes select the slot in which they want to transmit. Once the satellite has received all the packets and based on the collisions that have occurred in the previous frame, it has to estimate the number of slots needed for the following one. This protocol requires time synchronisation between all the nodes. Figure 7 shows an example of the adaptative slots within a frame.

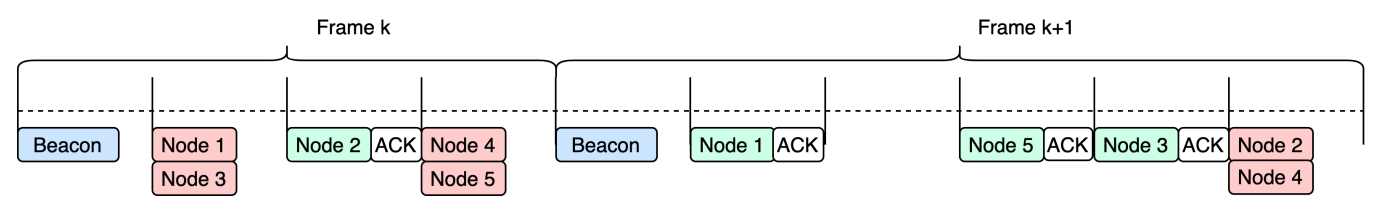

Figure 7. Sequence diagram for FC-TDMA protocol.

For this protocol, the beacon contains the sync and number of slots fields, and the ACK has only the common fields. For this protocol, the same assumption as with R-Aloha is taken for the beacon, since the medium is divided into frames and a beacon is sent, collision free, at the beginning of each frame. Thus, for our study, a periodicity of $1 \mathrm{~min}$ in the beacon is considered.

\section{Random Frequency Time Division Multiple Access (RFTDMA)}

In this protocol [74], the transmitter node selects a random carrier frequency within a range to transmit the packets and transmits them in a contention based manner in time. This protocol benefits from poor quality oscillators included in most IoT nodes since these oscillators can cause a deviation in the central frequency of the transmitted signal. It is especially useful for narrowband signals since the deviation in the carrier frequency separates the packets in the frequency domain.

Overall, along with the presentation of the different protocols the packets that are exchanged for each of them, and the fields sent in each one have been identified. This information is summarised in Table 2, and it is necessary to calculate the maximum number of nodes and their density. 
Table 2. Summary of types of packets interchanged in the network for each of the protocols, according to the sequence diagram.

\begin{tabular}{cccccc}
\hline Protocol & Slotted & Beacon & Control Packets & Data Packets & Acknowledgement \\
\hline Aloha & No & 80 bits & - & D & 104 bits \\
\hline E-Aloha & No & 96 bits & - & D & 104 bits \\
\hline SS-Aloha & No & 80 bits & - & D & 104 bits \\
\hline E-SSA & No & 80 bits & - & D & 104 bits \\
\hline S-Aloha & Yes & 96 bits & - & D & - \\
\hline CRDSA & Yes & 96 bits & - & F, G, H (redundant) & - \\
\hline IRSA & Yes & 96 bits & - & F, G (subpackets) & - \\
\hline CSA & Yes & 112 bits & - & D & 104 bits \\
\hline MuSCA & No & 96 bits & - & D & 120 bits \\
\hline CSMA $/ C A$ & No & 80 bits & 128 bits, 112 bits & D & 104 bits \\
\hline R-Aloha & Yes & 128 bits & - & D & 104 bits
\end{tabular}

\section{Capacity and Sensors Density Results}

Now that the packets are to be sent for each protocol and the sizes of the payloads are defined, it is necessary to add the LoRa modulation header and the cyclic redundancy check. To obtain this, first, the total number of symbols $\left(N_{S}\right)$ of each packet has to be calculated, as shown in Equation (1) [75].

$$
\begin{aligned}
& N_{\text {symbols }}=N_{s_{\text {preamble }}}+4.25+8+(C R+4) . \\
& \operatorname{ceil}\left(\frac{\text { max }\left(8 \cdot N_{s_{\text {payload }}}+N_{b_{C R C}}-4 \cdot S F+8+N_{s_{\text {header }}, 0}\right)}{4 \cdot S F}\right)
\end{aligned}
$$

Several fields have to be determined from the LoRa packet headers. Starting with the number of symbols in the preamble $\left(N_{s_{\text {preamble }}}\right)$, the standard value is 8 symbols. The next field is the number of symbols in the payload field $\left(N_{s_{\text {payload }}}\right)$, which are the values identified in Table 3, converted into symbols. The next field is the number of bits in the CRC $\left(N_{b_{C R C}}\right)$, which is by default fixed to 16 bits. Regarding the number of symbols in the header $\left(N_{s_{\text {header }}}\right)$, this value is set to 0 if the payload size is fixed, and to 20 symbols if the size of the payload is variable. Given that the size of the payload is variable for this application, it is necessary to include these 20 symbols of the header.

Finally, there are three modulation parameters: the bandwidth (BW), the spreading factor (SF), and the coding rate (CR). BW determines the bandwidth of the signal, and, based on the standard, it can be set to 125,250 , or $500 \mathrm{kHz}$. SF determines the chips in every symbol, having more chips for lower values of $\mathrm{SF}$, and as a consequence a higher data rate. SF can be fixed between 7 and 12. CR determines the redundancy every 4 bits, having a total of $5,6,7$, or 8 bits. The values of the SF and CR are based on a study of the physical layer of the LoRa modulation in the space-to-Earth communications environment [26]. These values are a $\mathrm{BW}=125 \mathrm{kHz}$, so that the Doppler can be compensated, an $\mathrm{SF}=8$, so that there is a high data rate, and a $C R=4 / 5$, having one bit of redundancy every four bits. In the case of CSA and MuSCA protocols, it is set to $\mathrm{CR}=4 / 8$, since these protocols require a higher redundancy at physical level.

Once all the fields and modulation parameters are fixed, the total number of symbols and bits of each of the packets can be computed, using Equation (1) to obtain the symbols, and then by multiplying the transmission time $\left(t_{t x}\right.$, Equation (4)) by the data rate $R_{b}$. The results of this calculation can be seen in Table 3 . These packet dimensions will be used to calculate the maximum number of nodes that can transmit over the network. 
Based on the size of the data packets, it ranges from 28 up to 38 symbols. For the rest of our study, we will consider the worst case of 38 symbols, since having longer packets means a lower density of nodes. To obtain the maximum number of nodes, the first step is to calculate the maximum capacity $\left(C_{\max }\right)$ that nodes can use of the network so that it does not saturate. To calculate $C_{\max }$, the maximum throughput $\left(S_{\max }\right)$ has to be multiplied by the raw capacity that the LoRa nodes can offer $\left(C_{\text {raw }}\right)$, (Equation (2)):

$$
C_{\max }=S_{\max } \cdot C_{\text {raw }} \text {. }
$$

Given that $S_{\max }$ is computed as the messages received divided by the total number of messages sent, it already considers the retransmissions that have to be done due to collisions when accessing the medium. Thus, with this $C_{\max }$ the mean transmission time of each of the packets for each protocol is calculated as (Equation (3)):

$$
\begin{gathered}
T_{t_{\text {mean }}}=C_{\text {max }} \cdot \text { Packet }_{\text {size }} . \\
t_{t x}=\frac{2^{S F}}{B W} \cdot N_{\text {symbol }} .
\end{gathered}
$$

The next step is to calculate the maximum number of nodes $\left(N_{\max }\right)$ for each of the protocols. This is calculated by considering the total time that the nodes have the satellite in view, subtracting the transmission time of the beacon, and dividing it by the transmission times of the other packets that are sent, such as control packets, data packets, and ACKs. This calculation is shown in Equation (5). If the protocol does not have control packets or ACKs the values of the corresponding $T_{t x}$ are set to zero.

$$
N_{\text {max }}=\frac{T_{\text {view }}-T_{t x_{\text {beacon }}}}{T_{t x_{\text {packet }}}+T_{t x_{\text {control }}}+T_{t x_{\text {acknowledgement }}}} .
$$

Table 3. Total packet sizes of all messages sent in the network.

\begin{tabular}{llll}
\hline \multirow{2}{*}{ Packet Type } & $\begin{array}{l}\text { Payload } \\
\text { Size (b) }\end{array}$ & $\begin{array}{l}\text { Packet Size } \\
\text { (Symbols) }\end{array}$ & $\begin{array}{l}\text { Packet } \\
\text { Size (b) }\end{array}$ \\
\cline { 2 - 4 } Beacon & 80 & 23 & 254 \\
\cline { 2 - 4 } & 96 & 23 & 254 \\
\cline { 2 - 4 } & 112 & 23 & 254 \\
\hline Floods & 128 & 28 & 290 \\
\hline Landslides & 168 & 33 & 326 \\
\hline Forest fires & 200 & 38 & 362 \\
\hline Sea ice & 184 & 38 & 362 \\
\hline Earthquakes & 208 & 38 & 362 \\
\hline Droughts & 136 & 28 & 290 \\
\hline Tsunamis & 184 & 38 & 362 \\
\hline \multirow{2}{*}{ ACK } & 168 & 33 & 326 \\
\hline RTS & 104 & 28 & 290 \\
\hline CTS & 120 & 28 & 290 \\
\hline
\end{tabular}

Following the aforementioned calculations, the value of $N_{\max }$ in the footprint of the satellite simultaneously is given in Table 4 . As part of this table, $S_{\max }, C_{\max }$, and $U_{\max }$ are given for the case study where the data packets send 38 symbols. 
Table 4. Maximum number of nodes $N_{\max }$ allowed within the footprint of the satellite simultaneously.

\begin{tabular}{llll}
\hline Protocol & $S_{\max }$ & $\boldsymbol{C}_{\max }(\mathbf{b p s})$ & $\boldsymbol{N}_{\max }$ \\
\hline E-ALOHA & 0.091 & 159.96 & 117 \\
\hline RFTDMA & 0.1 & 175.78 & 129 \\
\hline Aloha & 0.184 & 323.43 & 237 \\
\hline SS-Aloha & 0.3 & 527.34 & 388 \\
\hline CRDSA & 0.52 & 914.06 & 403 \\
\hline R-Aloha & 0.368 & 646.87 & 472 \\
\hline S-Aloha & 0.368 & 646.87 & 476 \\
\hline CSMA/CA & 0.8 & 1406.25 & 548 \\
\hline IRSA & 0.8 & 1406.25 & 621 \\
\hline CSA & 0.8 & 1406.25 & 1163 \\
\hline FC-TDMA & 1 & 1757.81 & 1291 \\
\hline E-SSA & 1.2 & 2109.37 & 2797 \\
\hline MuSCA & 1.4 & 2460.93 & 3264 \\
\hline
\end{tabular}

Having the maximum number of nodes, the next step is to determine the density of nodes that can be achieved with each of the protocols, so that it can be related to the requirements identified in Section 3. This density is strictly depending on the footprint size of the antenna, and this footprint depends on the antenna's directivity and the satellite orbital height. Thus, to make the results more general, the density is provided for different footprint sizes, so that the footprint size can be extrapolated to LEO satellites orbits, or even other types of platforms, such as high altitude balloons (HAPs), or drones.

Results are shown in Table 5 and are classified with a colour scale based on the density of nodes per every $1000 \mathrm{~km}^{2}$. Additionally, in Figure 8 a graphical representation of the densities achieved can be seen.

Table 5. Density of nodes for each MAC protocol for applications that send 38 symbol packets.

\begin{tabular}{lcccccc}
\hline \multicolumn{7}{c}{ Nodes Density $\left(\mathbf{N o d e s} / \mathbf{1 0 0 0} \mathbf{~ k m}^{\mathbf{2}}\right)$} \\
\hline Protocol & $\mathbf{5 0} \times \mathbf{5 0}$ & $\mathbf{1 0 0} \times \mathbf{1 0 0}$ & $\mathbf{2 0 0} \times \mathbf{2 0 0}$ & $\mathbf{3 0 0} \times \mathbf{3 0 0}$ & $\mathbf{4 0 0} \times \mathbf{4 0 0}$ & $\mathbf{5 0 0} \times \mathbf{5 0 0}$ \\
\hline E-ALOHA & 46.98 & 11.74 & 2.94 & 1.30 & 0.73 & 0.47 \\
\hline RFTDMA & 51.64 & 12.91 & 3.23 & 1.43 & 0.81 & 0.52 \\
\hline Aloha & 95.15 & 23.79 & 5.95 & 2.64 & 1.49 & 0.95 \\
\hline SS-Aloha & 155.23 & 38.81 & 9.70 & 4.31 & 2.43 & 1.55 \\
\hline CRDSA & 161.60 & 40.40 & 10.10 & 4.49 & 2.52 & 1.62 \\
\hline R-Aloha & 189.18 & 47.30 & 11.82 & 5.26 & 2.96 & 1.89 \\
\hline S-Aloha & 190.45 & 47.61 & 11.90 & 5.29 & 2.98 & 1.90 \\
\hline CSMA/CA & 219.22 & 54.80 & 13.70 & 6.09 & 3.43 & 2.19 \\
\hline IRSA & 248.66 & 62.17 & 15.54 & 6.91 & 3.89 & 2.49 \\
\hline CSA & 465.58 & 116.39 & 29.10 & 12.93 & 7.27 & 4.66 \\
\hline FC-TDMA & 516.53 & 129.13 & 32.28 & 14.35 & 8.07 & 5.17 \\
\hline E-SSA & 1119.12 & 279.78 & 69.95 & 31.09 & 17.49 & 11.19 \\
\hline MuSCA & 1305.69 & 326.42 & 81.61 & 36.27 & 20.40 & 13.06 \\
\hline
\end{tabular}




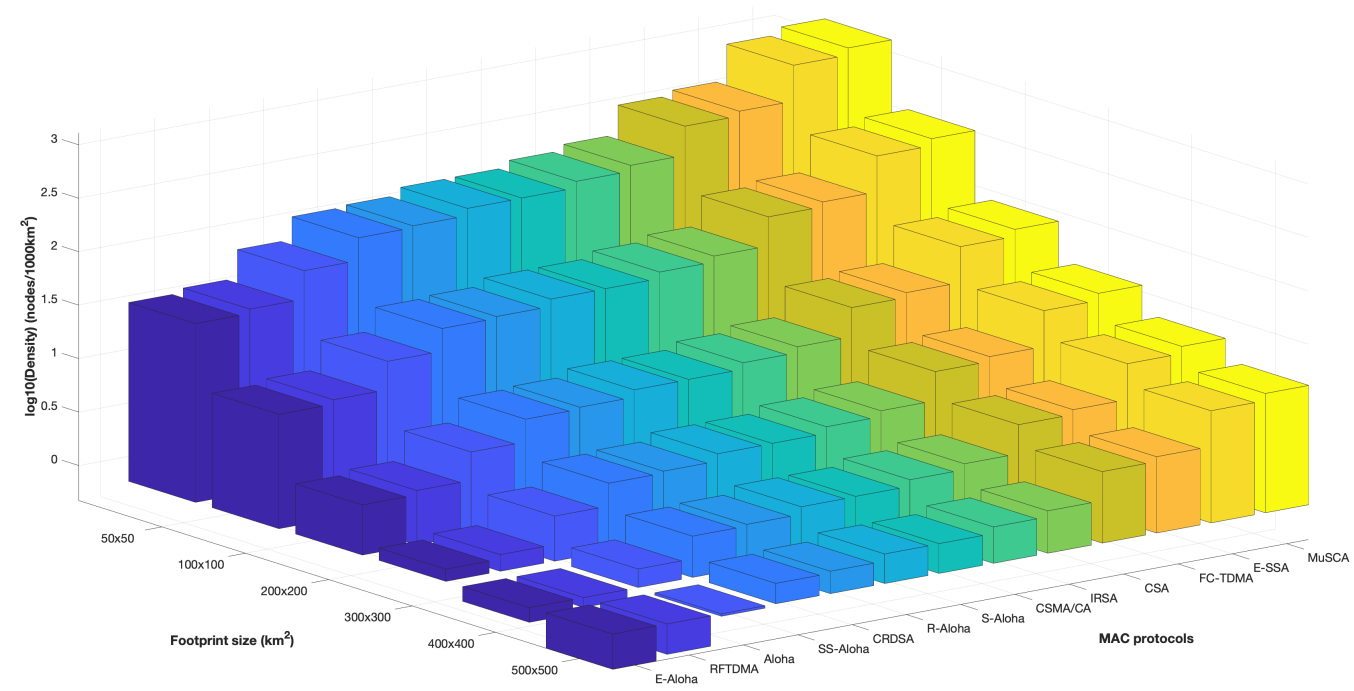

Figure 8. Graphic representation of the density of nodes for each MAC protocol for applications that send 38 symbols.

\section{Discussion}

Overall, our study has presented the density of nodes achievable with different MAC layer mechanisms, specific for IoT satellite communications. This allows assessing the requirements identified for natural disaster monitoring in Section 3. As it can be seen all requirements can be fulfilled, which demonstrates the feasibility of the on-demand executions strategy. Applying this strategy is beneficial since natural disasters can be detected early and monitored both in-situ and remotely.

Taking a closer look at the results from Table 5 , and comparing them with the requirements identified in Table 1 it can be seen that the densities are identified with a colour tag, and the following density ranges: over 1000, between 1000 and 100, between 100 and 10, and below 10 nodes $/ \mathrm{km}^{2}$. Following, an analysis of each of these ranges is performed comparing the requirements with the suitable protocols.

Starting with the case of a density over 1000 nodes $/ \mathrm{km}^{2}$, the two cases that are within this range are floods, and landslides $\left(1273\right.$ nodes $\left./ \mathrm{km}^{2}\right)$. For these cases, the only protocol that can be used is MuSCA with a footprint of $50 \times 50 \mathrm{~km}^{2}$. However, if the requirements were more relaxed also the E-SSA protocol could be used.

Following with 1000 up to 100 nodes $/ \mathrm{km}^{2}$ range, there are also two requirements for forest fires, and for sea ice being 318 nodes $/ \mathrm{km}^{2}$. The protocols that can fulfill the requirements are MusCa with a footprint of $100 \times 100 \mathrm{~km}^{2}$, and CSA, FC-TDMA, and E-SSA with a footprint of $50 \times 50 \mathrm{~km}^{2}$. To select the most suitable, there is a trade-off between the footprint size and the complexity of the protocol, depending on what can be implemented in the satellite and nodes. Smaller footprints require a bigger and more complex antenna, and more complex protocols require extra processing resources. Thus, if the objective is to have a simpler antenna the MuSCA protocol is the best option. In case the objective is to optimise the processing, the best option would be the FC-TDMA protocol since CSA requires to divide packets into subpackets, and E-SSA includes an interference cancellation algorithm, requiring more processing.

The next case is for densities between 100 and 10 nodes $/ \mathrm{km}^{2}$, the requirement that is in this range is for earthquakes with a density of 36 nodes $/ \mathrm{km}^{2}$. For this density, the protocols that could be used are MusCa with a footprint of $300 \times 300 \mathrm{~km}^{2}$, and E-SSA with $200 \times 200 \mathrm{~km}^{2}$ footprint. Additionally, with a footprint of $100 \times 100 \mathrm{~km}^{2}$ the protocols FC-TDMA, CSA, IRSA, CSMA/CA, S-Aloha, R-Aloha, CRDSA, and SS-Aloha could be used. Finally, for a footprint of $50 \times 50 \mathrm{~km}^{2}$ the protocols Aloha, RFTDMA, and E-ALOHA can be used. In this particular scenario, MuSCA is the best option if the complexity of the antenna wants to be low. Either Aloha or S-Aloha can be used if processing wants to be optimised since the usage of these two protocols is broadly extended. 
Finally, for scenarios below 10 nodes $/ \mathrm{km}^{2}$, there is drought with 0.1 nodes $/ \mathrm{km}^{2}$, and tsunamis with 0.004 nodes $/ \mathrm{km}^{2}$. In this case, all protocols can be used with a footprint of $500 \times 500 \mathrm{~km}^{2}$. Thus, the best option for implementation simplicity and processing resources would be to use the Aloha protocol.

\section{Conclusions}

This study has presented a novel strategy for disasters monitoring of flooding, landslides, fires, sea ice monitoring, earthquakes, drought, and tsunamis, based on an ondemand execution of the satellite payload. This approach optimises the use of both in-situ and spaceborne instruments. In order to quantify the proposed strategy for each disaster, the different types of IoT in-situ sensors, the spatial density, and update frequency requirements have been evaluated, and also whether or not these requirements can be met with existing MAC protocols specific for IoT satellite communications.

Having such a large quantity of sensors that may try to send their data and request a satellite payload execution poses a challenge in terms of MAC layer. Thus, as part of this study, a review on different MAC protocols has been conducted, identifying which protocols are more suitable for IoT satellite communications environment. For each protocol, the particular implementation for this case study is provided, identifying the packets exchanged and their sizes, and the sequence diagram. Then, the maximum number of nodes and the density have been evaluated and compared with the identified monitoring requirements. The antenna footprint depends on the antenna directivity, and the altitude of the platform, varying from $50 \times 50 \mathrm{~km}^{2}$ to $500 \times 500 \mathrm{~km}^{2}$.

In general, it can be seen that the predictions fulfill the spatial density requirements to monitor natural disasters. Regarding the update frequency requirements, these are related and will determine the size of the constellation. Some companies are already launching IoT satellite constellations (e.g., Lacuna Space [76], Fossa Systems [77], or SatelIoT [78]), which can be a good asset to monitor natural disasters.

Author Contributions: Conceptualisation, L.F., J.A.R.-d.-A., A.C. (Anna Calveras), and A.C. (Adriano Camps); methodology, L.F., A.C. (Anna Calveras), and A.C. (Adriano Camps); software, L.F.; validation, J.A.R.-d.-A., A.C. (Anna Calveras), and A.C. (Adriano Camps); formal analysis, L.F., A.C. (Anna Calveras), and A.C. (Adriano Camps); investigation, L.F., A.C. (Anna Calveras), and A.C. (Adriano Camps); resources, A.C. (Anna Calveras) and A.C. (Adriano Camps); data curation, L.F.; writing —original draft preparation, L.F.; writing — review and editing, L.F., J.A.R.-d.-A., A.C. (Anna Calveras), and A.C. (Adriano Camps); visualisation, L.F.; supervision, J.A.R.-d.-A., A.C. (Anna Calveras), and A.C. (Adriano Camps); project administration, A.C. (Anna Calveras), and A.C. (Adriano Camps); funding acquisition, A.C. (Anna Calveras) and A.C. (Adriano Camps). All authors have read and agreed to the published version of the manuscript.

Funding: This work was supported by the Spanish Ministry of Economy and Competitiveness, by the Spanish Ministry of Science, Innovation and Universities, "Sensing with Pioneering Opportunistic Techniques", grant RTI2018-099008-B-C21/AEI/10.13039/501100011033, also funded in part by the ERDF and the Spanish Government through project PID2019-106808RA-I00 AEI/FEDER UE, and by Secretaria d'Universitats i Recerca del Departament d'Empresa i Coneixement de la Generalitat de Catalunya 2017 SGR 376 and 2017 SGR 219. This work has also been founded by the Government of Catalonia in the scope of the NewSpace Strategy for Catalonia. Finally, this research was possible thanks to the FI-2019 grant from AGAUR-Generalitat de Catalunya.

Acknowledgments: The authors would like to thank all NanoSat Lab members who supported this work. Additionally, the first author would like to thank all other authors for their support and advice.

Conflicts of Interest: The authors declare no conflicts of interest.

\section{References}

1. World Meteorological Organization. The Global Telecommunication System (GTS). Available online: https://short.howpublished. at/FGJKS (accessed on 21 June 2021).

2. National Oceanic and Atmospheric Administration. National Data Buoy Center. Available online: https://www.ndbc.noaa.gov/ (accessed on 21 June 2021). 
3. National Oceanic and Atmospheric Administration. How Can Realtime Data Be Retrieved from the NDBC Web Site? Available online: https:/ / www.ndbc.noaa.gov/rt_data_access.shtml (accessed on 21 June 2021).

4. National Oceanic and Atmospheric Administration. Find Your Local Tides and Currents. Available online: https:// tidesandcurrents.noaa.gov/map/index.html (accessed on 21 June 2021).

5. ShakeAlert. ShakeAlert: An Earthquake Early Warning System for the West Coast of the United States. Available online: https:/ / www.shakealert.org/ (accessed on 21 June 2021).

6. Lancheros, E.; Camps, A.; Park, H.; Rodriguez, P.; Tonetti, S.; Cote, J.; Pierotti, S. Selection of the Key Earth Observation Sensors and Platforms Focusing on Applications for Polar Regions in the Scope of Copernicus System 2020-2030. Remote. Sens. 2019, 11, 175. [CrossRef]

7. NASA. MODIS. Available online: https://modis.gsfc.nasa.gov/about/ (accessed on 21 June 2021).

8. Fire Detection Maps. Available online: https://fsapps.nwcg.gov/afm/activefiremaps.php?sensor=goes\&extent=conus (accessed on 21 June 2021).

9. Djepa, V. Drought prediction using the Along Track Scanning Radiometer (ATSR2) on board ERS2 satellite. Adv. Space Res. 2011, 48, 56-60. [CrossRef]

10. The European Space Agency. Sentinel-1. Available online: https://sentinel.esa.int/web/sentinel/missions/sentinel-1 (accessed on 21 June 2021).

11. The European Space Agency. Sentinel-1 Acquisition Modes. Available online: https://sentinel.esa.int/web/sentinel/technicalguides/sentinel-1-sar/sar-instrument/acquisition-modes (accessed on 21 June 2021).

12. The Value of Geoinformation for Disaster and Risk Management (VALID). Available online: https://un-spider.org/about/ publication/value-geoinformation-disaster-and-risk-management-valid (accessed on 21 June 2021).

13. Ferrer, T.; Céspedes, S.; Becerra, A. Review and Evaluation of MAC Protocols for Satellite IoT Systems Using Nanosatellites. Sensors 2019, 19, 1947. [CrossRef]

14. Centenaro, M.; Costa, C.E.; Granelli, F.; Sacchi, C.; Vangelista, L. A Survey on Technologies, Standards and Open Challenges in Satellite IoT. IEEE Commun. Surv. Tutor. 2021, 23, 1693-1720. [CrossRef]

15. CubeSat. Available online: http:/ / www.cubesat.org/ (accessed on 21 June 2021).

16. Selva, D.; Krejci, D. A survey and assessment of the capabilities of Cubesats for Earth observation. Acta Astronaut. 2012, 74, 50-68. [CrossRef]

17. Stephens, G.; Freeman, A.; Richard, E.; Pilewskie, P.; Larkin, P.; Chew, C.; Tanelli, S.; Brown, S.; Posselt, D.; Peral, E. The Emerging Technological Revolution in Earth Observations. Bull. Am. Meteorol. Soc. 2020, 101, E274-E285. [CrossRef]

18. Mekki, K.; Bajic, E.; Chaxel, F.; Meyer, F. A comparative study of LPWAN technologies for large-scale IoT deployment. ICT Express 2019, 5, 1-7. [CrossRef]

19. Qu, Z.; Zhang, G.; Cao, H.; Xie, J. LEO Satellite Constellation for Internet of Things. IEEE Access 2017, 5, 18391-18401. [CrossRef]

20. Sigfox. Sigfox: The Global Communicator Service Provider. Available online: https://www.sigfox.com/en (accessed on 21 June 2021).

21. 3GPP. Release 13. Available online: https://www.3gpp.org/release-13 (accessed on 21 June 2021).

22. Alliance, L. Home Page I LoRa Alliance. Available online: https://lora-alliance.org/ (accessed on 21 June 2021).

23. LoRaWAN. LoRaWAN. Available online: https://lorawan.es/ (accessed on 21 June 2021).

24. Alliance, L. What Is LoRaWAN ${ }^{\circledR}$ Specification. Available online: https://lora-alliance.org/about-lorawan/ (accessed on 21 June 2021).

25. Doroshkin, A.A.; Zadorozhny, A.M.; Kus, O.N.; Prokopyev, V.Y.; Prokopyev, Y.M. Experimental Study of LoRa Modulation Immunity to Doppler Effect in CubeSat Radio Communications. IEEE Access 2019, 7, 75721-75731. [CrossRef]

26. Fernandez, L.; Ruiz-De-Azua, J.A.; Calveras, A.; Camps, A. Assessing LoRa for Satellite-to-Earth Communications Considering the Impact of Ionospheric Scintillation. IEEE Access 2020, 8, 165570-165582. [CrossRef]

27. Zahir, S.B.; Ehkan, P.; Sabapathy, T.; Jusoh, M.; Osman, M.N.; Yasin, M.N.; Wahab, Y.A.; Hambali, N.; Ali, N.; Bakhit, A.; et al. Smart IoT Flood Monitoring System. J. Phys. Conf. Ser. 2019, 1339, 012043. [CrossRef]

28. IOT Flood Monitoring \& Alerting System. Available online: https://nevonprojects.com/iot-flood-monitoring-alerting-system/ (accessed on 21 June 2021).

29. IoT. Flood Monitoring and Warning System. Available online: https://enviraiot.com/flood-monitoring-warning-system/ (accessed on 21 June 2021).

30. Butler, M.; Angelopoulos, M.; Mahy, D. Efficient IoT-enabled Landslide Monitoring. In Proceedings of the 2019 IEEE 5th World Forum on Internet of Things (WF-IoT), Limerick, Ireland, 15-18 April 2019; pp. 171-176. [CrossRef]

31. Moulat, M.E.; Debauche, O.; Mahmoudi, S.; Brahim, L.A.; Manneback, P.; Lebeau, F. Monitoring System Using Internet of Things For Potential Landslides. Procedia Comput. Sci. 2018, 134, 26-34. [CrossRef]

32. U.S. Landslides Inventory. Available online: https://usgs.maps.arcgis.com/apps/webappviewer/index.html?id=ae120962f459 434b8c904b456c82669d (accessed on 21 June 2021).

33. BEHR-TECH. 3 Remarkable IoT Applications for Fire Safety. Available online: https://behrtech.com/blog/3-remarkable-iotapplications-for-fire-safety/ (accessed on 21 June 2021).

34. Sharma, A.; Singh, P.; Kumar, Y. An Integrated Fire Detection System using IoT and Image Processing Technique for Smart Cities. Sustain. Cities Soc. 2020, 61, 102332. [CrossRef] 
35. Smith, G.C. Polar Ocean Observations: A Critical Gap in the Observing System and Its Effect on Environmental Predictions From Hours to a Season. Front. Mar. Sci. 2019, 6, 429. [CrossRef] [PubMed]

36. Lancheros, E.; Camps, A.; Park, H.; Sicard, P.; Mangin, A.; Matevosyan, H.; Lluch, I. Gaps Analysis and Requirements Specification for the Evolution of Copernicus System for Polar Regions Monitoring: Addressing the Challenges in the Horizon 2020-2030. Remote. Sens. 2018, 10, 1098. [CrossRef]

37. Xu, G.; Shi, Y.; Sun, X.; Shen, W. Internet of Things in Marine Environment Monitoring: A Review. Sensors 2019, $19,1711$. [CrossRef] [PubMed]

38. Smartice. Our System Provides Up-to-Date Information to Suit Community and Industry Specific Needs. Available online: https: / smartice.org/technology (accessed on 21 June 2021).

39. Liu, Q.; Jen, C.K.; Wu, K.T.; Kobayashi, M.; Mrad, N. In-situ ice and structure thickness monitoring using integrated and flexible ultrasonic transducers. Smart Mater. Struct. 2008, 17, 045023. [CrossRef]

40. Lee, J.; Khan, I.; Choi, S.; Kwon, Y.W. A Smart IoT Device for Detecting and Responding to Earthquakes. Electronics 2019, 8, 1546. [CrossRef]

41. Ravi, G. Earthquake Early Warning System by IOT using Wireless Sensor Networks. In Proceedings of the 2016 International Conference on Wireless Communications, Signal Processing and Networking (WiSPNET), Chennai, India, 23-25 March 2016; [CrossRef]

42. USGS. Latest Earthquakes. Available online: https:// earthquake.usgs.gov/earthquakes/map/ (accessed on 21 June 2021).

43. Kaur, A.; Sood, S.K. Cloud-Centric IoT-Based Green Framework for Smart Drought Prediction. IEEE Internet Things J. 2020, 7, 1111-1121. [CrossRef]

44. Drought.gov. Why Drought Early Warning? Available online: https://www.drought.gov/about/drought-early-warning (accessed on 21 June 2021).

45. Nimbargi, S.; Hadawale, S.; Ghodke, G. Tsunami alert \& detection system using IoT: A survey. In Proceedings of the 2017 International Conference on Big Data, IoT and Data Science (BID), Pune, India, 20-22 December 2017; pp. 182-184. [CrossRef]

46. Malhotra, G.; Virmani, D.D. Intelligent information retrieval in a Tsunami detection system using wireless sensor networks. In Proceedings of the 2016 International Conference on Computing, Communication and Automation (ICCCA), Greater Noida, India, 29-30 April 2016; pp. 939-944. [CrossRef]

47. NOOA. NOAA Tsunami Program. Available online: https://www.tsunami.noaa.gov/ (accessed on 21 June 2021).

48. ARGO. Available online: https:/ / argo.ucsd.edu/ (accessed on 21 June 2021).

49. National Weather Service. Tsunami Propagation. Available online: https://www.weather.gov/jetstream/tsu_prop (accessed on 21 June 2021).

50. Adelantado, F.; Vilajosana, X.; Tuset-Peiro, P.; Martinez, B.; Melia-Segui, J.; Watteyne, T. Understanding the Limits of LoRaWAN. IEEE Commun. Mag. 2017, 55, 34-40. [CrossRef]

51. Feltrin, L.; Buratti, C.; Vinciarelli, E.; De Bonis, R.; Verdone, R. LoRaWAN: Evaluation of Link- and System-Level Performance. IEEE Internet Things J. 2018, 5, 2249-2258. [CrossRef]

52. Bankov, D.; Khorov, E.; Lyakhov, A. On the Limits of LoRaWAN Channel Access. In Proceedings of the 2016 International Conference on Engineering and Telecommunication (EnT), Moscow, Russia, 29-30 November 2016; pp. 10-14. [CrossRef]

53. Ochoa, M.N.; Suraty, L.; Maman, M.; Duda, A. Large Scale LoRa Networks: From Homogeneous to Heterogeneous Deployments. In Proceedings of the 2018 14th International Conference on Wireless and Mobile Computing, Networking and Communications (WiMob), Limassol, Cyprus, 15-17 October 2018; pp. 192-199. [CrossRef]

54. Lee, J.; Jeong, W.C.; Choi, B.C. A Scheduling Algorithm for Improving Scalability of LoRaWAN. In Proceedings of the 2018 International Conference on Information and Communication Technology Convergence (ICTC), Jeju Island, Korea, 17-19 October 2018; pp. 1383-1388. [CrossRef]

55. Piyare, R.; Murphy, A.L.; Magno, M.; Benini, L. On-Demand TDMA for Energy Efficient Data Collection with LoRa and Wake-up Receiver. In Proceedings of the 2018 14th International Conference on Wireless and Mobile Computing, Networking and Communications (WiMob), Limassol, Cyprus, 15-17 October 2018; pp. 1-4. [CrossRef]

56. Hoeller, A.; Souza, R.D.; Alcaraz López, O.L.; Alves, H.; de Noronha Neto, M.; Brante, G. Analysis and Performance Optimization of LoRa Networks With Time and Antenna Diversity. IEEE Access 2018, 6, 32820-32829. [CrossRef]

57. Farooq, M.O.; Pesch, D. A Search into a Suitable Channel Access Control Protocol for LoRa-Based Networks. In Proceedings of the 2018 IEEE 43rd Conference on Local Computer Networks (LCN), Chicago, IL, USA, 1-4 October 2018; pp. 283-286. [CrossRef]

58. Peyravi, H. Medium Access Control Protocols for Space and Satellite Communications; Kent State University Kent, OH, USA, 2004.

59. ITU-R. Technical and Operating Parameters and Spectrum Use for Short-Range Radiocommunication Devices. Available online: https:/ / www.itu.int/dms_pub/itu-r/opb/rep/R-REP-SM.2153-2-2011-PDF-E.pdf (accessed on 21 June 2021).

60. Kuo, F.F. The ALOHA system. ACM SIGCOMM Comput. Commun. Rev. 1974, 4, 5-8. [CrossRef]

61. Ma, H.; Cai, L. Performance analysis of randomized MAC for satellite telemetry systems. In Proceedings of the 20105 th International ICST Conference on Communications and Networking in China, Beijing, China, 25-27 August 2010; pp. 1-5.

62. Herrero, O.; Foti, G.; Gallinaro, G. Spread-spectrum techniques for the provision of packet access on the reverse link of next-generation broadband multimedia satellite systems. IEEE J. Sel. Areas Commun. 2004, 22, 574-583. [CrossRef]

63. Abramson, N. Multiple access in wireless digital networks. Proc. IEEE 1994, 82, 1360-1370. [CrossRef] 
64. De Gaudenzi, R.; del Rio Herrero, O.; Gallinaro, G. Enhanced spread Aloha physical layer design and performance. Int. J. Satell. Commun. Netw. 2014, 32, 457-473. [CrossRef]

65. Polonelli, T.; Brunelli, D.; Benini, L. Slotted ALOHA Overlay on LoRaWAN: A Distributed Synchronization Approach. In Proceedings of the 2018 IEEE 16th International Conference on Embedded and Ubiquitous Computing (EUC), Bucharest, Romania, 29-31 October 2018.

66. Casini, E.; De Gaudenzi, R.; Del Rio Herrero, O. Contention Resolution Diversity Slotted ALOHA (CRDSA): An Enhanced Random Access Schemefor Satellite Access Packet Networks. IEEE Trans. Wirel. Commun. 2007, 6, 1408-1419. [CrossRef]

67. Liva, G. Graph-Based Analysis and Optimization of Contention Resolution Diversity Slotted ALOHA. IEEE Trans. Commun. 2011, 59, 477-487. [CrossRef]

68. Paolini, E.; Liva, G.; Chiani, M. Coded Slotted ALOHA: A Graph-Based Method for Uncoordinated Multiple Access. IEEE Trans. Inf. Theory 2015, 61, 6815-6832. [CrossRef]

69. Bui, H.C.; Lacan, J.; Boucheret, M.L. An enhanced multiple random access scheme for satellite communications. In Proceedings of the Wireless Telecommunications Symposium 2012, London, UK, 18-20 April 2012; pp. 1-6. [CrossRef]

70. Bianchi, G.; Fratta, L.; Oliveri, M. Performance evaluation and enhancement of the CSMA/CA MAC protocol for 802.11 wireless LANs. In Proceedings of the PIMRC '96-7th International Symposium on Personal, Indoor, and Mobile Communications, Taipei, Taiwan, 18 October 1996; Volume 2, pp. 392-396. [CrossRef]

71. Crowther, W.; Rettberg, R.; Walden, D.; Ornstein, S.; Heart, E. A system for broadcast communication: Reservation-ALOHA. In Proceedings of the 6th Hawaii International Conference on Systems Sciences, Honolulu, HI, USA, 9-11 January 1973.

72. Lam. Packet Broadcast Networks-A Performance Analysis of the R-ALOHA Protocol. IEEE Trans. Comput. 1980, C-29, 596-603. [CrossRef]

73. Luan, P.; Zhu, J.; Gao, K. An improved TDMA access protocol in LEO satellite communication system. In Proceedings of the 2016 IEEE International Conference on Signal Processing, Communications and Computing (ICSPCC), Hongkong, China, 5-8 August 2016; pp. 1-4. [CrossRef]

74. Goursaud, C.; Mo, Y. Random unslotted time-frequency ALOHA: Theory and application to IoT UNB networks. In Proceedings of the 2016 23rd International Conference on Telecommunications (ICT), Thessaloniki, Greece, 16-18 May 2016; pp. 1-5. [CrossRef]

75. Semtech. SX1261/2 Data Sheet DS.SX1261-2.W.APP; Rev. 1.1.; Semtech: Camarillo, CA, USA, 2018.

76. Lacuna Space. Available online: https://www.lacuna.space/ (accessed on 21 June 2021).

77. Fossa Systems. Available online: https:/ / fossa.systems/es/home-spanish/ (accessed on 21 June 2021).

78. SATELIOT. 5G IoT from Space. Available online: https:/ / sateliot.space/ (accessed on 21 June 2021). 